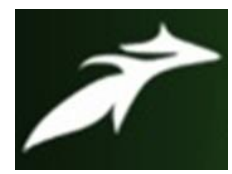

L. Allwin et al, International Journal of Advances in Agricultural Science and Technology,

Vol.8 Issue.9, September-2021, pg. 106-113

ISSN: 2348-1358

Impact Factor: 6.057

NAAS Rating: 3.77

\title{
COMPARATIVE BIOLOGY AND PREDATORY POTENTIAL OF \\ Cryptolaemus montrouzieri ON MEALYBUGS
}

\author{
L. Allwin ${ }^{1}$; V. Radhakrishnan ${ }^{2}$ \\ ${ }^{1}$ Assistant Professor, Regional Research Station, TNAU, Vridhachalam, Cuddalore District - 606001 \\ ${ }^{2}$ Programme Coordinator, ICAR - KVK, TNAU, Needamangalam, Thiruvarur District 614 404, Tamil Nadu \\ Corresponding Authors email: allwin.dr@gmail.com \\ DOI: 10.47856/ijaast.2021.v08i9.012
}

\begin{abstract}
Comparative biology of Cryptolaemus montrouzieri on Maconellicoccus hirsutus and Pseudococcus citri revealed that it had completed its life cycle successfully on both species. The mean total developmental period (egg to pupa) was 18.1 days, when reared on $P$. citri and it was 20.9 days in $M$. hirsutus. The adults developed on $P$. citri had high fecundity 284.2 eggs / female and longevity 47.0 days than those developed on M. hirsutus. Analysis on the growth indices of $C$. montrouzieri showed more preference on $P$. citri with high suitability index of 2.51 than $M$. hirsutus (1.78). Among two life stages, adults of $C$. montrouzieri was more voracious and each adult consumed an average 258.7, 352.1 and 217.3 numbers on $M$. hirsutus while, it was 323.8, 715.6 and 328.6 number of eggs, nymphs and adults for $P$. citri, respectively. The grubs required 221.1, 55.1 and 36.6 numbers of $M$. hirsutus and 1079.0, 341.3 and 41.0 number of eggs, nymphs and adults of $P$. citri, respectively to complete life stages. Out of different instars of $C$. montrouzieri, third and fourth instars required around 92.1, 78.5 and 85.9 per cent and 88.9, 93.5 and 79.0 per cent of total eggs, nymphs and adults of $P$. citri and $M$. hirsutus consumed, respectively.
\end{abstract}

Keywords: Biology, Cryptolaemus montrouzieri, mealybugs, predatory potential, instars.

\section{Introduction}

Coccinellids and many predators have the potential to harbor a diversity of parasites and pathogens under natural conditions. Generally, feeds on phytophagous insects and mites and could be well utilized in biocontrol programs. Whitecomb (1940) and Oncuer and Baylan (1982) in their findings stated that the Cryptolaemus montrouzieri grub consumed about 1325 to 3330 eggs of Pseudococcus citri. Mani and Thontadarya (1987) indicated that the C. montrouzieri grub consumed a total of 881.3 eggs or 259.0 nymphs or 27.5 adult females of $M$. hirsutus under laboratory conditions. Babu and Azam (1988) proved that the daily consumption of eggs of M. hirsutus by $C$. montrouzieri was more at $30^{\circ} \mathrm{C}$ than at $20^{\circ} \mathrm{C}$. 


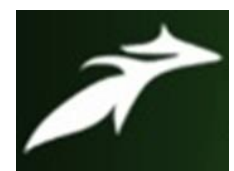

L. Allwin et al, International Journal of Advances in Agricultural Science and Technology,

Vol.8 Issue.9, September-2021, pg. 106-113

ISSN: 2348-1358

Impact Factor: 6.057

NAAS Rating: 3.77

However, the total number of eggs consumed during the entire larval period was found to be significantly greater at $20^{\circ} \mathrm{C}$.

Jayaraman et al. (1988) concluded that predatory rate of adults of $C$. montrouzieri on $M$. hirsutus and P. citri was higher than that of $S$. coccivora, irrespective of their sexes. The data on the biology and feeding potential of $C$. montrouzieri on different types of mealy bugs is very few. A comparative study on the biology and feeding potential of $C$. montrouzieri on two different mealybugs, Macronellicoccus hirsutus and Plannococcus citri was therefore, carried out at Tamil Nadu Agricultural University.

\section{Materials and Methods}

\subsection{Biology and growth indices of Cryptolaemus montrouzieri}

The cultures of $M$. hirsutus and $P$. citri maintained on pumpkin were used for studying the biology of $C$. montrouzieri. Eggs obtained from $C$. montrouzieri were allowed to complete one generation on the respective hosts and were used for biological and predatory potential studies. Twenty-five fresh eggs were taken separately from the surface of M. hirsutus and P. citri infested pumpkin. Egg period was calculated by recording the day of oviposition and day of emergence. After eclosion, first instar grubs started to feed mealybugs and the developmental period for each instar was recorded by observing the moulted exuviae. Pupae of $C$. montrouzieri were collected and kept in adult emergence cage for the pupal period. Observations on pupal weight, adult emergence and sex ratio were made by the method (Sunil Joshi et al., 1999). Various growth indices were calculated based on the data generated on biological parameters of $C$. montrouzieri on two mealybugs.

\subsection{Predatory potential of $C$. montrouzieri on $M$. hirsutus and P. citri}

The predatory potential of grub and adult of $C$. montrouzieri was studied on M. hirsutus and P. citri (Radke et al., 1977). Experiment was conducted to determine the rate of consumption on different stages of mealybugs (eggs, nymphs and adults) by the predatory grubs. After hatching, each grub was confined in a polypot and provided with known number of host insects. Observations were made at $24 \mathrm{~h}$ interval and surviving host insects were 


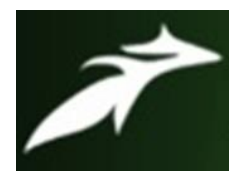

L. Allwin et al, International Journal of Advances in Agricultural Science and Technology, Vol.8 Issue.9, September-2021, pg. 106-113

ISSN: 2348-1358

Impact Factor: 6.057

NAAS Rating: 3.77

counted and removed. Fresh hosts were offered to the predatory grub until pupation. Number of host insects consumed by the grub in each instar and the total consumption during grub period were calculated. The feeding potential studies were conducted with ten grubs considering each one as replication.

Similarly to determine the rate of consumption on different stages of mealybugs (eggs, nymphs and adults) by the adults of $C$. montrouzieri, each adult was confined in a polypot and provided with known number of mealybugs. The number of mealybugs preyed by the adults / day was counted at $24 \mathrm{~h}$ interval till the adults were alive.

\section{Results and Discussion}

C. montrouzieri had successfully completed its life cycle on M. hirsutus and $P$. citri The mean egg period of $C$. montrouzieri when reared on $P$. citri was $4.2 \pm 0.3$ days and $3.7 \pm 0.4$ days for $M$. hirsutus. Uniformly four grub instars were observed on both mealybugs, $M$. hirsutus and $P$. citri with a average duration of first, second, third and fourth instars lasting $3.0 \pm 0.3,1.3 \pm 0.2,3.2 \pm 0.2$ and $3.8 \pm 0.4$ days, respectively on P. citri and $2.9 \pm 0.3,2.4 \pm 0.2,3.3 \pm 0.3$ and $3.9 \pm 0.4$ days on $M$. hirsutus. The mean grub period of $C$. montrouzieri averaged $11.5 \pm 1.0$ and $12.6 \pm 0.6$ days on P. citri and M. hirsutus, respectively. The prepupal and pupal period of $C$. montrouzieri lasted $1.7 \pm 0.3$ and $4.9 \pm 0.6$ days and $1.8 \pm 0.3$ and $6.5 \pm 0.3$ days on P. citri and M. hirsutus, respectively (Table 1). C. montrouzieri showed more feeding preference on P. citri than M. hirsutus.

Table 1. Developmental periods of $C$. montrouzieri reared on $M$. hirsutus and $P$. citri

\begin{tabular}{|l|c|c|}
\hline \multirow{2}{*}{ Life stages of C. montrouzieri } & \multicolumn{2}{|c|}{ Developmental periods* on } \\
\cline { 2 - 3 } & M. hirsutus & P. citri \\
\hline Egg (days) & $3.7 \pm 0.4$ & $4.2 \pm 0.3$ \\
Grub (days) & & \\
\multicolumn{1}{|c|}{ I } & $2.9 \pm 0.3$ & $3.0 \pm 0.3$ \\
\hline
\end{tabular}




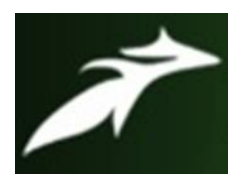

L. Allwin et al, International Journal of Advances in Agricultural Science and Technology,

Vol.8 Issue.9, September-2021, pg. 106-113

ISSN: 2348-1358

Impact Factor: 6.057

NAAS Rating: 3.77

\begin{tabular}{|l|c|c|}
\hline \multicolumn{1}{|c|}{ II } & $2.4 \pm 0.2$ & $1.4 \pm 0.2$ \\
\multicolumn{1}{|c|}{ III } & $3.3 \pm 0.3$ & $3.2 \pm 0.2$ \\
IV & $3.9 \pm 0.4$ & $3.8 \pm 0.4$ \\
Total grub period (days) & $\mathbf{1 2 . 6} \pm \mathbf{0 . 6}$ & $\mathbf{1 1 . 5} \pm \mathbf{1 . 0 5}$ \\
Prepupal period (days) & $1.8 \pm 0.3$ & $1.7 \pm 0.3$ \\
Pupal period (days) & $6.5 \pm 0.3$ & $4.9 \pm 0.6$ \\
Total developmental period (days) & $\mathbf{2 0 . 9} \pm \mathbf{5 . 4}$ & $\mathbf{1 8 . 1} \pm \mathbf{5 . 0}$ \\
Pupation (\%) & $76.0 \pm 0.6$ & $86.0 \pm 0.2$ \\
Adult emergence (\%) & 100 & 100 \\
Fecundity (Nos.) & $227.4 \pm 11.5$ & $284.2 \pm 3.4$ \\
Sex ratio (q: ${ }^{\top}$ ) & $1: 0.5$ & $1: 0.5$ \\
Oviposition period (days) & $29.5 \pm 0.7$ & $34.7 \pm 0.8$ \\
Longevity & $40.7 \pm 1.5$ & $47.0 \pm 1.0$ \\
Weight of Pupa (mg) & $1.3 \pm 0.03$ & $1.4 \pm 0.04$ \\
Weight of adult (mg) & $11.2 \pm 0.07$ & $11.4 \pm 0.06$ \\
\hline
\end{tabular}

*Mean of five replications

C. montrouzieri took $18.1 \pm 5.0$ days from egg to pupa when reared on P. citri while it was $20.9 \pm 5.4$ days on $M$. hirsutus. Although there was a slight variation in per cent pupation of $C$. montrouzieri with $8.6 \pm 0.2$ and $7.6 \pm 0.6$ days on P. citri and $M$. hirsutus, respectively, cent per cent adult emergence was recorded on two prey species studied (Table 1). C. montrouzieri had a maximum fecundity of $284.2 \pm 3.4$ eggs / female on P. citri in a oviposition period of $34.7 \pm 0.8$ days which was $227.4 \pm 11.5$ eggs/ female on $M$. hirsutus with a oviposition period of $29.5 \pm 0.7$ days. The sex ratio observed was 1: 0.5 . The adult of $C$. montrouzieri survived for $47.0 \pm 1.0$ days when reared on $P$. citri, whereas 


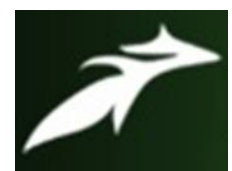

L. Allwin et al, International Journal of Advances in Agricultural Science and Technology, Vol.8 Issue.9, September-2021, pg. 106-113

ISSN: 2348-1358

Impact Factor: 6.057

NAAS Rating: 3.77

$40.7 \pm 1.5$ days on $M$. hirsutus. The average pupa and adult weight of $C$. montrouzieri were $1.4 \pm 0.04$ and $11.4 \pm 0.06 \mathrm{mg}$ on P. citri and $1.3 \pm 0.03$ and $11.2 \pm 0.07 \mathrm{mg}$ on M. hirsutus.

Studies on the growth indices of $C$. montrouzieri on $M$. hirsutus and $P$. citri by keeping one mealybug species as constant indicated that the predator showed more preference to $P$. citri with high suitability index of 2.51, than for M. hirsutus (1.78) (Table 2).

Table 2. Growth indices of $C$. montrouzieri on $P$. citri and $M$. hirsutus

\begin{tabular}{|l|c|c|}
\hline \multicolumn{1}{|c|}{ Life stages } & P. citri & M. hirsutus \\
\hline Larval-pupal index & - & 2.427 \\
\hline Pupal weight index & - & 1.080 \\
\hline Adult weight index & - & 1.016 \\
\hline Adult emergence index & - & 1.000 \\
\hline Development index & - & 0.864 \\
\hline General growth index & 7.50 & 6.013 \\
\hline Howe's growth index & 0.110 & 0.095 \\
\hline Suitability index & 2.51 & 1.78 \\
\hline
\end{tabular}

Data obtained for $P$. citri was used to calculate growth indices of $M$. hirsutus

Grubs and adults of $C$. montrouzieri required a total number of $479.8 \pm 102.5$, $407.2 \pm 151.6$ and $253.9 \pm 93.4$ eggs, nymphs and adults of $M$. hirsutus to complete their life stages while the requirement of $P$. citri was $1402.9 \pm 238.3,1056.9 \pm 291.8$ and $369.6 \pm 142.5$. 


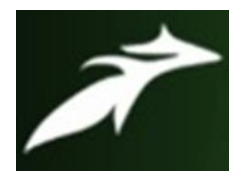

L. Allwin et al, International Journal of Advances in Agricultural Science and Technology, Vol.8 Issue.9, September-2021, pg. 106-113

ISSN: 2348-1358 Impact Factor: 6.057 NAAS Rating: 3.77

The adults of $C$. montrouzieri was able to consume on an average of $258.7 \pm 10.7$, $352.1 \pm 10.3$ and $217.3 \pm 5.0$ numbers of $M$. hirsutus, while it was $323.8 \pm 9.0,715.6 \pm 6.9$ and $328.6 \pm 7.8$ number of eggs, nymphs and adults of $P$. citri. The grub required $221.1 \pm 54.6,55.1 \pm 12.5$ and $36.6 \pm 8.9$ numbers and $1079.0 \pm 273.9,341.3 \pm 87.3$ and $41.0 \pm 7.2$ number of eggs, nymphs and adults of $M$. hirsutus and P. citri, respectively. Among various instars of the predator, third and fourth instar were voracious and consumed $91.3 \pm 10.4,11.1 \pm 1.1$ and $10.0 \pm 1.3$ number and $324.3 \pm 3.2,141.0 \pm 1.8$ and $13.5 \pm 1.4$ numbers of eggs, nymphs and adults of $M$. hirsutus. Whereas, the third and fourth instar were consumed 112.4 $\pm 23.2,32.1 \pm 1.6$ and $21.4 \pm 3.1$ numbers and $635.2 \pm 5.2,178.4 \pm 6.1$ and $18.9 \pm 1.7$ numbers of eggs, nymphs and adults of $P$. citri, respectively, which were 92.1, 78.5 and 85.9 per cent and 88.9, 93.5 and 79.0 per cent of total eggs, nymphs and adults of M. hirsutus and $P$. citri consumed, respectively. First and second instars consumed collectively 7.8, 21.4 and 14.0 per cent and 11.07, 6.4 and 20.9 per cent of eggs, nymphs and adults of $M$. hirsutus and $P$. citri, respectively. The consumption of first and second instar were $17.3 \pm 1.0,11.8 \pm 1.0$ and $5.1 \pm 0.9$ numbers and $119.5 \pm 8.3,21.8 \pm 2.3$ and $8.5 \pm 1.1$ numbers of eggs, nymphs and adults of $M$. hirsutus and $P$. citri, respectively (Table 3).

Table 3. Feeding potential of $C$. montrouzieri on $M$. hirsutus and P. citri

\begin{tabular}{|c|c|c|c|c|c|c|}
\hline \multirow{3}{*}{$\begin{array}{l}\text { Life stages of } \\
\text { C. montrouzieri }\end{array}$} & \multicolumn{6}{|c|}{ Numbers consumed $($ Mean \pm SD) } \\
\hline & \multicolumn{3}{|c|}{ M. hirsutus } & \multicolumn{3}{|c|}{ P. citri } \\
\hline & Egg & Nymph & Adult & Egg & Nymph & Adult \\
\hline Grub (Instar) & & & & & & \\
\hline I & $4.3 \pm 0.2$ & $4.6 \pm 0.6$ & $2.1 \pm 0.3$ & $\begin{array}{c}55.6 \pm \\
2.8\end{array}$ & $7.4 \pm 0.6$ & $3.3 \pm 0.3$ \\
\hline II & $13.0 \pm 0.8$ & $7.2 \pm 0.4$ & $\begin{array}{c}3.0 \pm \\
0.6\end{array}$ & $\begin{array}{c}63.9 \pm \\
5.5\end{array}$ & $14.4 \pm 1.7$ & $5.2 \pm 0.8$ \\
\hline III & $91.3 \pm 10.4$ & $11.1 \pm 1.1$ & $\begin{array}{c}10.0 \pm \\
1.3\end{array}$ & $\begin{array}{c}324.3 \pm \\
3.2\end{array}$ & $\begin{array}{c}141.0 \pm \\
1.8\end{array}$ & $13.5 \pm 1.4$ \\
\hline
\end{tabular}




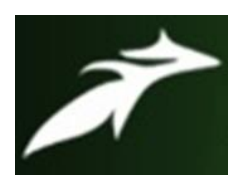

L. Allwin et al, International Journal of Advances in Agricultural Science and Technology,

Vol.8 Issue.9, September-2021, pg. 106-113

ISSN: 2348-1358

Impact Factor: 6.057

NAAS Rating: 3.77

\begin{tabular}{|c|c|c|c|c|c|c|}
\hline IV & $112.4 \pm$ & $32.1 \pm 1.6$ & $21.4 \pm$ & $635.2 \pm$ & $178.4 \pm$ & $18.9 \pm 1.7$ \\
& 23.2 & & 3.1 & 5.2 & 6.1 & \\
Total & $221.1 \pm 54.6$ & $55.1 \pm 12.5$ & $36.6 \pm$ & $1079.0 \pm$ & $341.3 \pm$ & $41.0 \pm$ \\
& & & 8.91 & 273.9 & 87.3 & 7.2 \\
Adult & $258.7 \pm 10.7$ & $352.1 \pm$ & $217.3 \pm$ & $323.8 \pm$ & $715.6 \pm$ & $328.6 \pm$ \\
& & 10.3 & 5.0 & 9.0 & 6.9 & 7.8 \\
& & & & & & \\
Total & $479.8 \pm$ & $407.2 \pm$ & $253.9 \pm$ & $1402.9 \pm$ & $1056.9 \pm$ & $369.6 \pm$ \\
consumption & 102.5 & 151.6 & 93.4 & 238.3 & 291.8 & 142.5 \\
\hline
\end{tabular}

Mean of ten replications

Studies on the development of $C$. montrouzieri on $M$. hirsutus and $P$. citri indicated that $C$. montrouzieri was able to complete its life cycle successfully on the above species but preferred more on $P$. citri than $M$. hirsutus. There was variation in the egg period of $C$. montrouzieri when reared on $P$. citri ( $4.2 \pm 0.3$ days) and $M$. hirsutus (3.7 \pm 0.4 days). The total grub period of $C$. montrouzieri was shortest $(11.5 \pm 1.0$ days) on $P$. citri which was extended by 1.1 days on $M$. hirsutus. The above findings are in consonance with (Cole, 1933) and (Manjula, 1998).

C. montrouzieri took $18.1 \pm 5.0$ and $20.9 \pm 5.4$ days from egg to pupa when reared on $P$. citri and M. hirsutus, respectively. The mean number of eggs per female was $284.2 \pm 3.4$ with oviposition period of $34.7 \pm 0.8$ days when reared on $P$. citri and $227.4 \pm 11.5$ with a oviposition period of $29.5 \pm 0.7$ days on M. hirsutus.. Similar observations were made by (Ruiz Castro, 1938) and (Niyazov, 1969). In India, Srinivasan (1987) observed that $C$. montrouzieri laid more number of eggs (252.6) when fed with P. citri than with M. hirsutus (204.9).

Grubs and adults of $C$. montrouzieri collectively required an average of 1402 eggs, 1056.9 nymphs and 369.6 adults of $P$. citri to complete its life stages indicating its high feeding preference on $P$. citri than $M$. hirsutus. The average number of eggs, nymphs and 


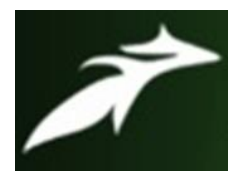

L. Allwin et al, International Journal of Advances in Agricultural Science and Technology,

Vol.8 Issue.9, September-2021, pg. 106-113

ISSN: 2348-1358

Impact Factor: 6.057

NAAS Rating: 3.77

adults consumed by $C$. montrouzieri was only 479.8, 407.2 and 253.9 numbers of $M$. hirsutus only. In all cases the highest feeding rate was observed by the fourth larval instar than other instars. This is in concurrence with the findings of Satyanarayanamurthy (1982). Similar findings were reported by (Kotikal and Sengonca, 1999) that all the stages of C. montrouzieri preferred $P$. citri than any other mealybugs. In the present investigations grubs and adults of $C$. montrouzieri consumed more number of nymphs than adults of $P$. citri which might be related to the body size of the nymphs and adults. The gradual increase in the feeding rate of older larvae might be due to their increased nutritional requirement.

\section{References}

[1]. Cole, F.R. (1933). Natural control of the citrus mealybug. Journal of Economic Entomolog, 26: 855964.

[2]. Jayaraman, V., Chandramohan, N., Gopalan, M., \& Balasubramanian, G. (1988). Predatory potential of coccinellid beetles on mealybugs of citrus and grapevine. Madras Agricultural Journal, 75 (1-2): 77-78.

[3]. Kotikal, Y.K., \& Sengonca, C. (1999). Olfactory responses of mealybug predator, Cryptolaemus montrouzieri Mulsant (Coleoptera: Coccinellidae) to the kairomones of prey arthropods, their host plants and the predator itself. Journal of Biological Control, 13: 1-6.

[4]. Mani, M \& Thontadarya, T.S. (1987). Devlopment and feeding potential of the coccinellid, Cryptolaemus montrouzieri Muls. on grape mealybug, Maconellicoccus hirsutus (Green). Journal of Biological Control, 1: 89-92.

[5]. Manjula, T.R. (1998). Studies on host preference, Impact on development and predatory potential of Australian lady bird beetle, Cryptolaemus montrouzieri Mulsant. M.Sc. (Ag.) Thesis, Tamil Nadu Agric. Univ., Coimabtore, India. 94p.

[6]. Niyazov, O.D. (1969). The parasites and predators of grape mealybug. Zash. Rast., $14: 38-40$.

[7]. Oncuer, C., \& Baylan, N. (1982). An investigation into the feeding capacity of C. montrouzieri. Turkiye Bitki Koruma Derges., 6: 85-90.

[8]. Radke, S.G., Barnad, W.L., \& Mundinale, S.K., (1977). Influence of age of predator, Coccinella septumpunctata L. and population density of host, Rhopalosiphum maidis Ftch. (Homoptera : Aphididae) on the of predation. Indian Journal of Agricultural Science, 47: 305-308.

[9]. Ruiz Castro, A. (1938). Experiments in the control of Pseudococcus citri Risso on the grapevine. Boletin Pathologia Vegetal Entomol. Agricola., 8: 162-170.

[10].Srinivasan, T.R. (1987). Studies on biology and control of grape mealybug, Maconellicoccus hirsutus Green. (Homoptera : Pseudococcidae). M.Sc.(Ag.) Thesis. Tamil Nadu Agric. Univ., Coimbatore, India. 56p.

[11].Satyanarayanamurthy, M. (1982). Studies on the biology and habits of Cryptolaemus montrouzieri Muls. (Coccinellidae : Coleoptera) Unpubl. M.Sc(Ag). Thesis, Andhra Pradesh Agric. Univ. Hyderabad.

[12]. Whitecomb, W.D. (1940). Biological control of mealybugs in green houses. Mass. Agric. Exp. Stn. Bull., 375: 22. 